Conclusions Severe RSV infection in high-risk infants represents a significant cause of morbidity and mortality and is associated with a high economic burden. Palivizumab was found to be cost-effective compared to no prophylaxis in the UK in all of the subgroups considered, demonstrating a good use of NHS resources.

\section{P171 IMPACT OF HEPTAVALENT PNEUMOCOCCAL CONJUGATE VACCINE ON THE INCIDENCE OF CHILDHOOD PNEUMONIA SEEN IN HOSPITAL IN THE NORTH EAST OF ENGLAND}

doi:10.1136/thoraxjnl-2011-201054c.171

${ }^{1} \mathrm{M}$ A Elemraid, ${ }^{2} \mathrm{~K}$ M Eastham, ${ }^{3} \mathrm{~S} P$ Rushton, ${ }^{3} \mathrm{M} \mathrm{D} F$ Shirley, ${ }^{4} \mathrm{D}$ A Spencer, ${ }^{4} \mathrm{M} F$ Thomas, ${ }^{5} \mathrm{~F}$ Hampton, ${ }^{6} \mathrm{R}$ Gorton, ${ }^{1} \mathrm{~K}$ Pollard, ${ }^{1} \mathrm{~A}$ R Gennery, ${ }^{1} \mathrm{~J}$ E Clark. ${ }^{1}$ Department of Paediatric Infectious Disease and Immunology, Newcastle upon Tyne Hospitals NHS Foundation Trust, Newcastle, UK; ${ }^{2}$ Department of Paediatrics, Sunderland Royal Hospital, Sunderland, UK; ${ }^{3}$ School of Biology, Newcastle University, Newcastle, UK; ${ }^{4}$ Department of Respiratory Paediatrics, Newcastle upon Tyne Hospitals NHS Foundation Trust, Newcastle, UK; ${ }^{5}$ Department of Paediatrics, James Cook University Hospital, Middlesbrough, UK; ${ }^{6}$ Regional Epidemiology Unit, Health Protection Agency North East, Newcastle, UK

Background Community-acquired pneumonia (CAP) is a common childhood infection. In September 2006, heptavalent pneumococcal conjugate vaccine (PCV7) was added into the UK national immunisation programme. Data from this study were compared with those from a similar study undertaken in the same hospitals in 2000-2001 to describe the disease epidemiological trend.

Aim To evaluate the impact of PCV7 on the incidence of all causes childhood CAP.

Methods A prospective population-based study including 11 hospitals in the North East of England from August 2008 to July 2009 Eligible cases were all children aged $0-16$ years who presented with clinical and radiological features of pneumonia. Demographic and clinical details were recorded.

Results Five hundred and seventy-six cases were initially identified, 34 of them had normal chest $\mathrm{x}$-ray and were removed after validation, leaving a total of 542 cases eligible for enrolment $(57.7 \%$ males; $73.8 \%$ under-five). The rate of empyema complication was $5.3 \%$. Lobar consolidation was reported in $29.9 \%$, and pleural effusion was present in $9.6 \%$ of the chest x-rays. PCV7 uptake was $88.9 \%$ among the eligible group, which is similar to that recorded nationally in the NHS Immunisation Statistics for England 2008-2009. In comparison with the data from 2001 study, there were $28 \%$ fewer cases of CAP in 2009 study. The incidence of CAP decreased from 14.4 cases per 10000 children in 2001 to 11.8 cases per 10000 children in 2009 (95\% CI 0.74 to 0.92 ).

Conclusion This study suggests that following the introduction of PCV7, the incidence of childhood pneumonia seen in hospital has decreased since 2001

\section{P172 CHANGES IN PNEUMOCOCCAL SEROTYPE DISTRIBUTION OF PAEDIATRIC EMPYEMA IN THE AGE OF PNEUMOCOCCAL CONJUGATE VACCINES}

doi:10.1136/thoraxjnl-2011-201054c.172

${ }^{1} \mathrm{M} F$ Thomas, ${ }^{2} \mathrm{C} L$ Sheppard, ${ }^{3} \mathrm{M}$ Guiver, ${ }^{2} \mathrm{R} C$ George, ${ }^{4} \mathrm{C}$ Simmister, ${ }^{4} \mathrm{D}$ Cliff, ${ }^{5} \mathrm{R}$ Gorton, ${ }^{1} \mathrm{M}$ A Elemraid, ${ }^{4} \mathrm{~J}$ E Clark, ${ }^{1} \mathrm{~S}$ P Rushton, ${ }^{6} \mathrm{~J}$ Y Paton, ${ }^{4} \mathrm{D}$ A Spencer. ${ }^{1}$ Newcastle University, Newcastle upon Tyne, UK; ${ }^{2}$ Respiratory and Systemic Infection Laboratory, Health Protection Agency, London, UK; ${ }^{3}$ Health Protection Agency North West, Manchester, UK; ${ }^{4}$ Newcastle upon Tyne Hospitals NHS Foundation Trust, Newcastle upon Tyne, UK; ${ }^{5}$ Health Protection Agency North East, Newcastle upon Tyne, UK; ${ }^{6}$ University of Glasgow, Glasgow, UK

Introduction Pneumococcal infection is the leading cause of paediatric empyema in the UK. The seven valent pneumococcal vaccine (PCV-7) was introduced to the UK routine immunisation schedule in September 2006 and replaced in April 2010 with a 13 valent
Abstract P172 Table 1

\begin{tabular}{llll}
\hline Serotype & $\begin{array}{l}\mathbf{2 0 0 6 / 2 0 0 7} \\
(\mathbf{n = 7 4 )}\end{array}$ & $\begin{array}{l}\mathbf{2 0 0 9 / 2 0 1 0} \\
(\mathbf{n = 1 0 7 )}\end{array}$ & $\begin{array}{l}\text { Incidence rate } \\
\text { ratio (95\% CI) }\end{array}$ \\
\hline 1 & 46 & 50 & $1.09(0.71$ to 1.66$)$ \\
3 & 11 & 35 & $3.18(1.58 \text { to } 6.93)^{*}$ \\
4 & 1 & 0 & $0.33(0$ to 15.41$)$ \\
5 & 0 & 2 & $4.99(0.21$ to 6625$)$ \\
$7 \mathrm{~A} / \mathrm{F}$ & 0 & 10 & $20.96(1.83 \text { to } 22872)^{*}$ \\
14 & 6 & 0 & $0.08(0 \text { to } 1.00)^{*}$ \\
$19 \mathrm{~A}$ & 5 & 7 & $1.40(0.38$ to 5.58$)$ \\
$23 \mathrm{~F}$ & 1 & 0 & $0.33(0$ to 15.41$)$ \\
$6 \mathrm{~A} / \mathrm{C}$ & 0 & 1 & $2.99(0.07$ to 4600$)$ \\
$6 \mathrm{~B}$ & 3 & 0 & $0.14(0$ to 2.52$)$ \\
$9 \mathrm{~V}$ & 1 & 0 & $0.33(0$ to 15.41$)$ \\
Non-assay serotype & 0 & 2 & $4.99(0.21$ to 6625$)$
\end{tabular}

\begin{tabular}{lccc}
\hline Serotype & $\begin{array}{l}\mathbf{2 0 0 6 / 2 0 0 7} \\
(\mathbf{n = 7 4 )}\end{array}$ & $\begin{array}{l}\mathbf{2 0 0 9 / 2 0 1 0} \\
(\mathbf{n = 1 0 7 )}\end{array}$ & p Value \\
\hline PCV-7 & & & \\
PCV-7 serotypes & $12(16 \%)$ & 0 & $<0.001$ \\
Non PCV-7 serotypes & $62(84 \%)$ & $107(100 \%)$ & \\
PCV-13 & & & 0.68 \\
PCV-13 serotypes & $107(98 \%)$ & $2(1.8 \%)$ & \\
Non PCV-13 serotypes & $108(96 \%)$ & $4(3.6 \%)$ & \\
\hline
\end{tabular}

*Denotes statistical significance.

vaccine (PCV-13). Concerns have been raised in several countries about serotype replacement disease in paediatric empyema following the introduction of PCV-7. We have monitored changes in pneumococcal serotype distribution to determine whether there is evidence of serotype replacement in culture negative paediatric empyema in England following introduction of PCV-7 and PCV-13. Methods In September 2006, the Health Protection Agency established enhanced surveillance of paediatric culture negative empyema for England in collaboration with members of the British Paediatric Respiratory Society. Samples were forwarded from admitting hospitals, those that were pneumococcal PCR positive underwent nonculture serotyping using a multiplex antigen detection assay capable of detecting 14 serotypes/groups $(1,3,4,5,6 \mathrm{~A} / \mathrm{C}, 6 \mathrm{~B}, 7 \mathrm{~F} / \mathrm{A}, 8,9 \mathrm{~V}, 14,18$, 19A, 19F and 23F). Fisher's exact test was used for analysis of count data and incidence rate ratios calculated for individual serotypes.

Results 420 pleural fluid samples from 413 patients were tested. Four serotypes/groups contributed more than $85 \%$ of the total serotypes detected (Serotype $1-42.4 \%, 3-24.3 \%, 7 \mathrm{~A} / \mathrm{F}-10.2 \%$ and $19 \mathrm{~A}-8.8 \%$ ). Changes in individual serotypes and overall counts are shown in Abstract P172 table 1. PCV-7 serotypes initially contributed $16 \%$ of those detected but in 2009/2010 none were detected ( $p<0.001$ ). There was an increase in the detection of non-PCV-13 serotypes in 2010/2011 although this rise was non-significant (Pre: $1.8 \%$, Post $3.6 \%, \mathrm{p}=0.68$ ). Conclusions No PCV-7 serotypes were detected in the final year before it was replaced by PCV-13, suggesting that PCV-7 was effective in preventing empyema due to these serotypes. There were significant increases in non-vaccine serotypes/groups, notably 3 and $7 \mathrm{~A} / \mathrm{F}$, consistent with serotype replacement disease and mirroring changes in invasive pneumococcal disease as a whole. The increase in disease caused by non-PCV-13 serotypes in 2010/2011 highlights the need for ongoing active surveillance. Future changes in serotype distribution are likely, and these may alter the clinical profile of empyema.

\section{P173 COMPARISON OF PRIMARY PLEURAL DRAINAGE STRATEGIES IN PAEDIATRIC EMPYEMA}

doi:10.1136/thoraxjnl-2011-201054c.173

${ }^{1} \mathrm{M} F$ Thomas, ${ }^{2} \mathrm{C}$ Simmister, ${ }^{2} \mathrm{D}$ Cliff, ${ }^{1} \mathrm{M}$ A Elemraid, ${ }^{2} \mathrm{~J} E$ Clark, ${ }^{1} \mathrm{~S} P$ Rushton, ${ }^{3} \mathrm{R}$ Gorton, ${ }^{4} \mathrm{~J}$ Y Paton, ${ }^{2} \mathrm{D}$ A Spencer. ${ }^{7}$ Newcastle University, Newcastle upon Tyne, 